\title{
Effect of Diagnostic Remedial Teaching Strategy on Students' Achievement in Biology
}

\section{Sam Oluseyi Oyekan, Ph.D}

\author{
Department of Special Education and Curriculum Studies \\ Adeyemi College of Education, Ondo, Ondo State, Nigeria. \\ +2348035802881, seyoyekan@yahoo.com
}

\author{
Doi:10.5901/jesr.2013.v3n7p282
}

\begin{abstract}
The study investigated the effect of diagnostic remedial teaching strategy on students' achievement in Biology. The purpose of the study was to diagnose and remedy identified students' weaknesses in Biology by comparing their performances in Conventional Teaching Method (CTM) and Diagnostic Remedial Teaching (DRT) strategy. A sample of 12 teachers and 427 randomly selected SS2 students was drawn from three secondary schools in each of the four selected Local Government Areas in Osun and Oyo States of Nigeria. A pretest-posttest control group design with the students randomly assigned into experimental, conventional teaching and control groups was utilized for the study. Two instruments titled Error Patterns Among Biology Students (EPABS), and Test of Achievement in Biology (TAB) were developed, validated and used for data collection. The findings of this study largely showed that the use of DRT is more effective in improving the students' achievement and retention than the CTM in Biology classroom practices. Hence, the diagnosis, knowledge and correction of identified students' weaknesses can strengthen Biology teachers with necessary teaching competence, behaviour and innovation required to rescue the students from learning difficulties.
\end{abstract}

Keywords: Diagnostic remediation, achievement, retention, biology, Nigeria

\section{Introduction}

Science and technology are inevitable forces in the current drive towards a guarantee of good life, peace, security and survival of mankind. This had led governments, private organisations and individuals to invest on the teaching of science and scientific researches particularly in Nigeria to promote, hold and sustain the interests, needs and aspirations of our children, youths and teachers in science (Oyekan, 1984; Federal Republic of Nigeria, 2004; Gbore \& Daramola, 2013). Such a hopeful desire might be hindered by the surging students' underachievement (Aghenta, 1982, Shuell, 1986; Widlake, 1984; Ibe \& Maduabum, 2001), outrageous development of anti-science culture and evolution of scientifically illiterate citizenry (Ogunniyi, 1986), and despicable school and home conditions (Oyekan, 1993). With reference to secondary school science, students steadily record the worst performance in the school certificate biology (WAEC, 1982; Soyibo, 1982; STAN, 1987; Oyekan, 1995; Gbore and Daramola, 2013). The relevance of biology to the corporate existence and survival of mankind should primarily impel a firm support from educators and teachers to seek a coherent instructional intervention that can diagnose and remedy the prevailing underachievement and apathy towards biology (Oyekan, 2005; Ahmad \& Asghar, 2011). Our action might be anchored on the interdisciplinary nature of biology which provides the requisite competence and experience to solve emerging problems in our living environment.

Diagnosis and remediation of students' weaknesses are the basic components of diagnostic remedial teaching (DRT). Herein diagnosis can be regarded as a technique to identify students' strengths and weaknesses in a lesson or course of study through tests, observations and projects. Data collected from diagnosis serve as the basis of an instructional needs analysis, and subsequently provide vital information which would enable a teacher to correct his/her methods, contents or presentation. Hence, remediation connotes an act of rectifying the students' learning difficulties or weaknesses which they experience with the school curriculum. This may be realized through inquiry-discovery (Bruner, 1966) and task analysis of learning experiences imbued with guidance in the planning of instruction (Gagne, 1977). It becomes imperative for the biology teacher to grasp adequate knowledge of the biological concepts and relate them with the requisite sequence, continuity and integration to the students' interest, needs and environment.

The feasibility of DRT strategy is rooted in the assumption that the achievement a learner attains might be influenced by pedagogical techniques which individual teachers use during instruction (Bekee, 1987; Bryant and Anderson, 1972). It is equally not unlikely that pupils would learn more, through enhanced learning efficiency and outcome, if they are better taught. Perhaps a flexible teaching method that inherently tends to accommodate students' 
cognitive styles (Oyekan, 1984) and rectify emerging weaknesses with continual practice, feedback and remedial instruction (Bajah and Bello, 1987) could become an inducement for optimal performance among the learners and teachers of biology. This might serve as an invaluable framework to plan and implement an effective and exciting curriculum for the bright and marginal students in the same classroom. Such efforts through the use of diagnostic remedial strategies can positively influence achievement (Yeany et al, 1980), provide effective guidance of learning, and evoke memory with conceptual understanding of biology.

Hence, effective teachers should scrutinize the problems associated with curricula and evaluation, and seek the basic features of good teaching with requisite enhancement of students' interests, achievement and inclination for further educations. The interactionist view of teaching is neatly capsulized by Brophy and Everton (1976):

Effective teaching requires the ability to implement a very large number of diagnostic, instructional, managerial and therapeutic skills, tailoring behaviour in specific contexts and situations to the specific needs of the moment (p. 139).

The teacher's professional commitment, creativity and imaginative ability are all indispensable towards effective diagnosis and remediation of students' weaknesses posing as potential learning difficulties in biology. Such attributes could help to provide clear teaching, accurate assessment and useful feedback that may boost the learning morale of biology learners beyond the classroom situations. This implies a veritable avenue to cope with emerging challenges in science and technology education.

This study focused on the current steady decline in performance, interest and choice of science subjects among Nigerian secondary school students. It was equally rooted in the realization that students' weaknesses centrally appear as powerful influence upon pupils' learning and achievement in biology. The situation had also been recognised to be inimical to the nation's scientific and technological advancement (STAN, 1987). Herein lies the necessity to exercise a great vigilance in identifying the sources of learning difficulties and provide appropriate remedial instruction before the students get into academic trouble (Mc Nicholas,1976; Mann,1986). A complete diagnosis and remediation of students' weaknesses, therefore, demands pooling all available resources by the school to make science and technology an integral part of our educational and national development. Adoption of DRT strategy could enhance the students' interest, performance and attitudes towards learning of biology. It may stand out as a force-runner of effective science teaching and indemnity against learning failure.

The following null hypotheses were generated for the study:

1. There is no significant difference in the performance of the CTM, DRT and CG students whether they were taught with the instructional guide and their weaknesses were remedied or not.

2. There is no significant difference in the performance of CTM and DRT students when they were both taught with the instructional guide.

3. There is no significant difference in the achievement of CTM, DRT and Control Group students on the retention test.

These hypotheses shall be used to verify collected data from the study sample as regards the effect of DRT strategy on students' achievement in biology.

\section{Method}

The study investigated the effect of diagnostic remedial teaching strategy on students' achievement in biology. A sample of 12 teachers and 427 randomly selected secondary school two (SS 2) students was drawn from three secondary schools in each of the four selected Local Government Areas in Osun and Oyo State of Nigeria. A pretest-posttest control group design with the students randomly assigned into experimental and control groups were utilized for the study. Hence, the SS2 students were divided into three instructional groups: Conventional Teaching Method (CTM), Diagnostic Remedial Teaching (DRT), and Control Group (CG).

In a Local Government Area, schools that made use of DRT and CTM approaches were designated as experimental groups. Also a school that did not utilize either DRT or CTM strategy was labelled as control group. Schools situated in both urban and rural areas of the selected Local Government were used to ensure a broad display of students' weaknesses in biology. The selection of the schools was based on stratified random sampling variables of location, sex, age and teacher availability. These characteristics helped largely in the spread of the schools, and preclusion of interaction among the experimental sample.

Two instruments titled Error Patterns Among Biology Students (EPABS), and Test of Achievement in Biology (TAB) were developed, content-validated and used for data collection. EPABS, a 22-item questionnaire, defined the 
construct of students' weaknesses in terms of observable students' behaviour (Oyekan, $1995 \mathrm{a}, \mathrm{b}$ ). The students recounted some pertinent students' weaknesses that often constitute impediments to their academic progress, achievement and interest in secondary school biology (Table 1).This compendium of identified students' weaknesses served as instructional template containing the components of learning experiences and objectives the instructional guide and TAB used by the 12 study teachers.

Table 1: Error patterns among biology students

\begin{tabular}{|c|l|}
\hline S/N & Students' Weaknesses \\
\hline 1 & Failure to draw well-labelled /annotated diagram(s) to illustrate/answer the chosen questions \\
\hline 2. & Instructions are not carefully read, strictly followed, and upheld to the last letter. \\
\hline 3. & Failure to write correct spellings especially in labels, identifications and one-word answers \\
\hline 4. & $\begin{array}{l}\text { Inability to interpret and apply basic facts and concepts appropriately and effectively in specific life } \\
\text { situations. }\end{array}$ \\
\hline 5. & Misconception in the popular notions of scientific facts, concepts or phenomena. \\
\hline 6. & Careless reading and misinterpretation of the questions \\
\hline 7. & Inadequate and scanty description(s) that lack details. \\
\hline 8. & Unnecessary concentration on and repetition of irrelevant materials and details \\
\hline 9. & $\begin{array}{l}\text { Inappropriate description of differences between organisms or specimens in tabular form with } \\
\text { corresponding distinguishing features and functions }\end{array}$ \\
\hline 10. & Confusion, misconception and misuse of appropriate terms, words or expressions. \\
\hline 11. & Lack of thorough knowledge and understanding of the subject matter and questions. \\
\hline 12. & Poor linguistic competence/inability to express thoughts in writing \\
\hline 13. & Improper descriptions and presentations of tests, observations and inferences in experiments \\
\hline 14. & Lack of basic knowledge of plant and animal forms and functions (adaptation) \\
\hline 15 & Poor drawings/representations, analysis, interpretation and application for graphical data. \\
\hline 16. & $\begin{array}{l}\text { Inability to apply basic principles and skills of mathematics correctly due to their poor manipulative and } \\
\text { interpretation skills in simple arithmetic. }\end{array}$ \\
\hline 17 & Failure to distribute time well. \\
\hline 18 & Inadequate preparation and poor learning \\
\hline 19. & Inadequate exposure to practical exercises. \\
\hline 20 & Failure to write or outline correct sequence of phenomena e.g. seed germination and urine formation. \\
\hline 21. & Failure to represent simple characters symbolically, particularly in genetics. \\
\hline 22. & Poor writing \\
\hline
\end{tabular}

Source: Oyekan, S.O (1995 a, b)

A compendium of these identified students' weaknesses could be adopted as potential components of learning experiences and objectives in meaningful biology lessons.

Test of Achievement in Biology (TAB), with an established reliability coefficient of 0.64 , was constructed by the researcher and content-validated with the senior school certificate (SSC) syllabus. TAB structurally was restricted to the assessment of biological concepts of seed germination and mammalian (human) reproduction for having empirical and theoretical dimensions. Furthermore, they were chosen because they have practical applications to quality human life and career interest to the students. The dependent variable in this study is students' achievement. Effectiveness of DRT strategy was measured in terms of the biology students' achievement using TAB. Twelve classroom biology teachers (4 for DRT, 4 for CTM, and 4 for Control Group) drawn from twelve schools in the four Local Governments were used for administering the instructional treatment and collecting data on students' weaknesses.

The DRT group teachers were familiar with the error patterns of SSC examination candidates from their teaching and marking experiences of biology. The CTM group teachers have no marking experience and were allowed to teach the students in accordance with the generally accepted instructional practices. They were not intimated with the highlighted students' weaknesses and possible examination expectations.

Control group teachers, however, did not teach but helped to administer the pretests and posttests. It implies that their students received no instructional treatment. This provided an avenue to compare and validate emerging results of DRT, CTM and CG students on TAB so as to ascertain the effectiveness of DRT strategy on students' achievement in biology. 
In the DRT group, emphasis was laid heavily on the correction of the identified students' weaknesses en block with practice questions to work upon. The students' responses were carefully guided and corrected on the basis of their emerging weaknesses. The subject matter for the CTM group was similar in content with that of DRT group. Fora for diagnosis and remediation of any students' weaknesses were tactically excluded in their instructional interactions. The selection, background experiences and learning environment of the CG were identical in all respect to the DRT and CTM groups except that their students did not receive any lesson on seed germination and human reproduction.

TAB administered on the DRT, CTM and Control groups' subjects as pretests and posttests was a composite of essay and objective test items. It was administered before and after instructional treatments in the classroom for duration of two lesson periods of 80 minutes. Analysis of collected data was carried out by using relative frequencies, percentages, t-test and analysis of variance to verify the hypotheses in the study.

\section{Results}

Analysis of data showed that there were error patterns depicting students' weaknesses among biology learners. It was also discovered that there were significant differences among the means of DRT, CTM and CG student on TAB; in the performance of DRT and CTM students before and after they were taught with the instructional guide; and in the achievement of the DRT and CTM students on retention test.

Hypothesis 1: There is no significant difference in the performance of CTM, DRT and CG students whether they were taught with instructional guide and their weaknesses were remedied or not.

Table 2: Posttest scores of CTM, DRT and CG students on TAB

\begin{tabular}{|c|c|c|c|c|}
\hline Instructional Groups & $\mathrm{N}$ & Achievement Scores $\sum X$ & $\bar{X}$ & S.D. \\
\hline CTM & 156 & 4967 & 31.84 & 15.23 \\
\hline DRT & 154 & 5575 & 36.23 & 13.74 \\
\hline Control & 117 & 3019 & 25.80 & 10.88 \\
\hline
\end{tabular}

The emerging groups' results show that DRT students with higher mean and lower standard deviation relatively performed better than CTM and CG students respectively on TAB. This provides explicit support for the effectiveness of progressive remediation of the students' weaknesses with the aid of DRT strategy.

Table 3: Analysis of variance of posttest achievement scores of the three groups

\begin{tabular}{|l|c|c|c|c|}
\hline Source of Variation & Sum of Squares (SS) & Degrees of Freedom (df) & Mean Square & Calculated F-Value Fc \\
\hline Between groups & 7189.92 & 2 & 3594.96 & 19.20 \\
\hline Within groups & 79406.23 & 424 & 187.28 & \\
\hline Total & 86596.15 & 426 & & \\
\hline
\end{tabular}

$\mathrm{F}_{\mathrm{t}}(\mathrm{df}=2,424 ; \mathrm{p}=0.05)=2.99$

Since the critical table value $F_{t}$ is less than $F_{c}$, the null hypothesis is rejected. This further shows that there was a significant difference among the group means of CTM, DRT and Control group students on TAB. As earlier indicated in Table 2, better performance was exhibited by DRT students on TAB in accordance with their higher mean score.

Hypothesis 2: There is no significant difference in the performance of CTM and DRT students when they were both taught with the instructional guide.

Table 4: Relationship between the achievement scores of CTM and DRT students

\begin{tabular}{|c|c|c|c|c|c|c|c|}
\hline & \multicolumn{4}{|c|}{ Posttest Scores } & Gain & Scores & t \\
\hline Instructional Group & $\mathrm{N}$ & $\sum X$ & $\bar{X}$ & S.D & $\sum X$ & $\bar{X}$ & IC \\
\hline $\begin{array}{l}\text { DRT } \\
\text { CTM }\end{array}$ & $\begin{array}{l}154 \\
156\end{array}$ & $\begin{array}{l}5575 \\
4967\end{array}$ & $\begin{array}{l}36.23 \\
31.84\end{array}$ & $\begin{array}{l}13.74 \\
15.23\end{array}$ & $\begin{array}{l}3496 \\
2313\end{array}$ & $\begin{array}{l}22.70 \\
14.83\end{array}$ & 102 \\
\hline
\end{tabular}

$t_{t}(d f=308, p=0.05)=1.96$

Since $t_{t}$ is less than $t_{c}$, the null hypothesis is rejected. This shows that there was a significant difference in the 
performance of CTM and DRT students when they were both taught with the instructional guide. The higher achievement mean and gain scores coupled with the lower standard deviation in the posttest scores of DRT students upheld the relative effectiveness of DRT on CTM strategy.

Hypothesis 3: There is no significant difference in the achievement of students on retention tests whether they were taught with instructional guide and their weaknesses were remedied or not.

Table 5: Comparison of the retention scores of the CTM, DRT and CG students on TAB

\begin{tabular}{|c|c|c|c|c|}
\hline Instructional Group & $\mathrm{N}$ & $\sum X$ & $\bar{X}$ & S.D \\
\hline CTM & 156 & 4733 & 30.34 & 13.89 \\
DRT & 154 & 6575 & 42.69 & 14.32 \\
CG & 117 & 2933 & 25.07 & 10.45 \\
\hline
\end{tabular}

The higher retention mean score achieved by DRT students showed the essence of identifying and correcting the students' weaknesses as teaching proceeds in classroom situations. It seems DRT is more effective than CTM in rectifying the learning problems and retaining more biological concepts over an instructional period of time.

Table 6: Analysis of variance of retention scores of CTM, DRT and CG students on TAB

\begin{tabular}{|c|c|c|c|c|}
\hline Source of Variation & $\begin{array}{c}\text { Sum of Squares } \\
(\mathrm{SS})\end{array}$ & $\begin{array}{c}\text { Degrees of } \\
\text { Freedom(df) }\end{array}$ & $\begin{array}{c}\text { Mean Square } \\
(\mathrm{MS})\end{array}$ & $\begin{array}{c}\text { Calculated } \\
\text { Fc }\end{array}$ \\
\hline Between groups & 22886.20 & 2 & 11443.10 & 65.24 \\
\hline Within Groups & 74367.11 & 424 & 175.39 & \\
\hline Total & 97253.31 & 426 & & \\
\hline
\end{tabular}

Since $\mathrm{F}_{\mathrm{t}}$ is less than $\mathrm{F}_{\mathrm{c}}$, the null hypothesis is rejected. This indicates that there was significant different among the group means of CTM, DRT and CG students on TAB. As earlier explained with Tables $4 \& 5$, the adoption of DRT strategy had significantly aided learning and retention of the biological concepts. This might have contributed immensely to the relative difference in the (higher) retention score attained by DRT students when compared with those accomplished by CMT and CG students respectively.

\section{Discussion}

The findings of this study largely showed that the use of DRT strategy is more effective in boosting the students' achievement and retention of biological concepts than the CTM in biology classroom practices. It is likely DRT provides the teacher with practical assistance to improve instruction, enhance learning, promote the actualization of unrealized human potential, and reduce the likelihood of a student failing to graduate or to further his/her education. Hence, biology teachers ought to embrace the practice of DRT strategy as an antidote to declining performance and interest in secondary school biology.

The choice of biology by students of varying abilities may demand the use of DRT strategy because of their interest in choosing it as one of the subjects for SSC examinations. Perhaps the preferential affinity for biology seems firmly rooted in the unique exploration and explanation of human life, natural phenomena and survival strategy it affords the students. This often attracts different categories of pupils choosing it just to have a credit pass or for post-secondary education in the agricultural, biological, medical, pharmaceutical science and allied disciplines. It is hoped that a biologically-literate citizen appreciate the virtues of good living, decent behaviour and sustainable environmental protection for the corporate survival and advancement of mankind.

\section{Conclusion}

The results of this study suggest the existence of a variety of difficulties students do have in coping with the learning of scientific facts and concepts in secondary school biology. Hence, the diagnosis, knowledge and application of identified students' weaknesses are potentially capable of suggesting effective ways of teaching learners of biology, matching them with appropriate learning tasks, and adapting instructional materials to their varying potentials.

Adoption of DRT strategy is more likely to reduce examination malpractices, promote good mental health and sustain 
better attitudes towards learning of biology. The increased students' achievement can provide able candidates for science and technology courses and responsible manpower to improve humanity and environment. It is envisioned that more students' interest and ability to acquire and apply biological knowledge to everyday life could improve our personal and community health for good lifestyle and healthy living, boost agricultural production for food security and industrial production, and preservation of biodiversity for a balanced living environment.

\section{References}

Aghenta, J,A, (1982) University administrations in Nigeria. Journal of Science Teachers Association of Nigeria, 20(2), 90-99.

Ahmad, R.N. \& Asghar, S.K. (2011). Attitude towards biology and its effects on students' achievement. International Journal of Biology. $3(4), 100-104$

Bajah, S.T. and Bello, O.O. (1987) The effect of enhanced problem-solving strategy on chemistry on students' achievement. Journal of Science Teachers Association of Nigeria, 25(2), 48

Bekee, F. (1987) Effects of behavioural objectives and diagnostic prescriptive teaching strategies on students' achievement in Integrated Science. Unpublished Ph.D Thesis, University of Ibadan, Ibadan, Nigeria.

Brophy, J.E. and Everton, C.M. (1976), Learning from teaching: A development perspective, Boston: Allyn and Bacon. p.139.

Bruner, J.S (1966) Toward a theory of instruction, Cambridge: Harvard University Press.

Bryant, N. and Anderson, H.A. (1972) Effects of performance objectives on achievement. Journal of Research in Science Teaching, 9(4),369-375

Federal Republic of Nigeria (2004) National policy on education, Lagos: NERDC Press

Gagne, R.M. (1977). Conditions of learning, New York: Holt, Reinhart and Winston.

Gbore, L.O \& Daramola, C.A. (2013) Relative contributions of selected teachers' variables and students' attitudes toward academic achievement in biology among Senior secondary school students in Ondo State, Nigeria, Current Issues in Education,16(1),1-9

Ibe, B.O. \& Maduabum, M.A (2001). Teacher's qualification and experience as correlates of secondary school students' achievement in biology. Journal of education thought, 1(2), 176-183.

Ogunniyi, M.B. (1986) Underachievement in science and emerging anti-science culture in Nigeria. Annual Conference Proceedings of Science Teachers Association of Nigeria, pp. 170-173.

Oyekan, S.O. (1984) Students' cognitive styles and achievement in biology, Unpublished M.A. Thesis, University of Ife, lle-lfe, Nigeria

Oyekan, S.O. (1993) Diagnosis of students' weaknesses: A conceptual framework for remediation of underachievement in science, Journal of Science Teachers' Association of Nigeria, 28(1\&2), 59-69.

Oyekan, S.O.(1995a) Effect of diagnostic remedial teaching strategy on students' achievement in biology. Unpublished Ph.D Thesis, Ile-Ife, Nigeria: Obafemi Awolowo University

Oyekan, S.O.(1995 b)Analysis of antecedents to underachievement in science. Journal of Educational Advancement, 2(2), 49-61.

Oyekan, S.O. (1995c) A study of factors associated with the students' achievement in science, Ife Journal of Theory and Research in Education, 4(1\&2), 95-106.

Oyekan, S.O. (2005) Critical imperatives for quality instruction and achievement in biology, School of Education Journal, 1,123-133

Soyibo, K. (1982) Relationship between school certificate pupils' attitudes and their achievement in biology, Journal of Science Teachers' Association of Nigeria, 20(2), 26-32

Shuell, T.J. (1986) Individual differences: changing conceptions in research and practice. American Journal of Education, 94(3), 356-377

STAN (1987) Resolution of the 28th Annual conference of the science teachers' association of Nigeria, STAN Bulletin, 5(1), 3.

WAEC (1982) Chief examiners' report: May/June GCE (O/L), Lagos: West African Examinations Council, pp.80-117.

Widlake, P. (1984) Beyond the sabre-toothed curriculum: Remedial Education, 19(1), 9-38

Yeany, R.H., Dost, R.J. and Mathews, R.W. (1980) The effects of diagnostic-prescriptive instruction and locus of control on the achievement and attitudes of university student. Journal of Research in Science Teaching, 17(5), 537-545. 